\title{
Into the Dustbin of History? The Evaluation and Preservation of Slavic Materials
}

\section{Bradley L. Schaffner and Brian J. Baird}

One of the greatest challenges facing area studies librarians today is preservation of collections. Area studies collections in libraries, the backbone of international studies programs for most colleges and universities in North America, are in danger. Most materials in these collections were published on acidic paper and poorly bound leaving them susceptible to rapid deterioration. Slavic collections, for example, appear to be in dire need of preservation treatment, but there is very little hard data on the scope of the problem. This research project, conducted at the University of Kansas Libraries, is the first step toward gaining a better understanding of the overall condition of Slavic collections. A survey of the Slavic holdings was conducted to provide statistical information on their physical condition. Results of the survey reveal that the condition of these collections should be cause for serious concern. However, the problems are not so great that they cannot be overcome through careful preservation planning and interlibrary cooperation.

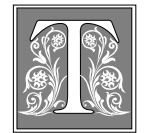

he "internationalization" and "globalization" of educational curricula and library holdings is currently of great interest to educators, scholars, and librarians. Barbara J. Ford, who recently completed her term as president of the ALA, championed the theme "Global Reach-Local Touch" to draw attention to the importance of an international perspective for American librarians and library collections. Although globalization is currently a hot topic among librarians and scholars, international area studies collections in academic and research libraries have effectively internationalized library holdings for many years. These area collec- tions, which include Slavic, Asian, African, and Latin American studies, to name a few, have been actively developed since World War Two or earlier. Some of the publications held in these collections date to the eighteenth century. The age of these collections brings the issue of their preservation to the forefront. Ironically, it is not the age of the publication that determines its remaining life span but, rather, the quality of materials used in its production. Unfortunately, most materials in area studies collections were published on acidic paper with poor-quality bindings. These factors, more than age, lead to their rapid deterioration. Today, area studies librarians must face the challenge of pre-

Bradley L. Schaffner is Russian Studies Librarian at the University of Kansas Libraries; e-mail: bschaffn@ukans.edu. Brian J. Baird is Preservation Librarian at the University of Kansas Libraries; email: bbaird@ukans.edu. 
serving these collections or watching them turn to dust.

This challenge is particularly evident in the field of Slavic studies. Scholars and librarians who work with Slavic materials have long known of the generally poor physical quality of publications from East Central Europe and the countries of the former Soviet Union. During the Soviet period, and even up to the present time, publications were/are printed on poorquality acidic paper. This type of paper, which is often similar to newsprint, deteriorates rapidly and becomes brittle, often crumbling when touched. In addition, a poor binding can shorten a book's usable life to between twenty and fifty years.

\section{Fortunately, there are many major Slavic collections in academic libraries outside the former Soviet Union where storage conditions are often more favorable.}

Exacerbating the problem of substandard publishing materials is the environment in which materials are housed. Most libraries in East Central Europe, particularly in the countries of the former Soviet Union, were not designed to preserve materials. Heating and cooling systems are inadequate or nonexistent, ventilation is poor, and many libraries have leaky roofs and plumbing problems. Moreover, many collections are located in buildings that were not intended to store books, such as private residences, churches, and office buildings. ${ }^{1}$ Poor storage conditions greatly accelerate the deterioration of any published material, and those produced with inferior materials have no chance of surviving under such conditions! If nothing is done to improve the storage environment, it is possible that many books published before, during, and after the Soviet period will not be available to future generations of scholars researching Slavic studies-a sad irony given this new era of political and social liberalization and openness in East Central Europe.

Fortunately, there are many major Slavic collections in academic libraries outside the former Soviet Union where storage conditions are often more favorable. However, although the physical conditions of most Western library facilities that house Slavic collections are good, preservation is still a major issue. Storing acidic materials under optimal conditions will increase their usable life by decades, but this does not negate the need for a proactive approach to reformatting embrittled materials. $^{2}$

Reformatting is accomplished by transferring the information in the original item to microfilm, digital images, or preservation-quality photocopy facsimiles. Whatever the approach, it is clear that preservation activities must take place in both the countries of the former Soviet Union and abroad. Even though the largest collections abroad have better storage facilities, they cannot rival the holdings of the major in-country libraries, such as the 40 million volumes in the Russian State Library in Moscow. Coordinated efforts among countries, universities, and libraries would facilitate the preservation of a substantial portion of important Slavic publications.

Most Slavic librarians would agree that the overall condition of materials in their Slavic collections is poor. This perception is based primarily on simple observation and anecdotal information. Very little work has been done to analyze the current condition and quality of Slavic publications. A few recent published reports do outline preservation programs in Russia and Bulgaria but devote little or no space to an evaluation of the physical condition of collections held by libraries in these countries. ${ }^{3}$

The research project conducted at the University of Kansas Libraries is the first step toward gaining a better understanding of the overall conditions of Slavic collections. It is important to understand the magnitude of the problem before developing a comprehensive preservation program. Information gathered in this survey will be used to help determine the best courses of action to preserve these important area collections. 


\begin{tabular}{|c|c|}
\hline \multicolumn{2}{|c|}{$\begin{array}{c}\text { TABLE } 1 \\
\text { Call Number Table }\end{array}$} \\
\hline LC Call Numbers & Dewey Call Numbers \\
\hline \multicolumn{2}{|c|}{ Russia/Soviet/Former Countries of the Soviet Union } \\
\hline \multicolumn{2}{|c|}{ History } \\
\hline DK1 to DK293 & 947 to 947.9507 \\
\hline \multicolumn{2}{|l|}{ DK501 to DK973 } \\
\hline \multicolumn{2}{|c|}{ Language and Literature } \\
\hline PG2001 to PG2847 & 491.7 to 491.799 \\
\hline PG2900 to PG3520 & 891.7 to 891.78 \\
\hline PG3801 to PG3957 & 891.79 to 891.798 \\
\hline \multicolumn{2}{|c|}{ Poland } \\
\hline \multicolumn{2}{|c|}{ History } \\
\hline D765.A36 to D765.2.C446 & 914.38 to 914.38 \\
\hline D802.P6 to D802.P62 & 940.53437 to 940.53485 \\
\hline DS135.P6 to DS135.P63 & \\
\hline DK401 to DK443.7 & \\
\hline DK4010 to 4800 & 943.8 to 943.86 \\
\hline \multicolumn{2}{|c|}{ Language and Literature } \\
\hline PG6001 to PG7365 & 891.85 to 891.858 \\
\hline
\end{tabular}

a timely random sampling of the entire 300,000 Slavic volumes housed throughout the University of Kansas library system, which would have required sampling every thousandth Slavic volume distributed throughout the libraries' three million volume collection. Therefore, the survey focused on the history and literature collections (DK, PG, and the Dewey equivalents) because most of the materials in these call number ranges were published in Slavic countries. The survey was further limited to Russian/Soviet/ post-Soviet history and literature and Polish history and literature (see table 1).

Soviet/Russian materials

The University of Kansas is home to one of eleven federally funded Department of Education Title VI comprehensive research centers for Slavic studies. The Slavic collections number more than 300,000 volumes, with strengths in Russian, Serbian, Croatian, Polish, and Ukrainian materials. Given the size of the collection, it would have been impossible to inspect each volume physically. Therefore, a statistically valid random survey was conducted. This Slavic survey is a modified version of a survey instrument previously used to evaluate the overall condition of collections at the University of Kansas Libraries. A description of the original survey process and its results was published in College \& Research Libraries. ${ }^{4}$ Because the general survey was developed to evaluate the condition of more than three million volumes, it did not provide sufficient detailed information on the physical condition of the Slavic collections.

To simplify the survey process, the evaluation focused on an area of the collection where a majority of the materials were published in Slavic countries. It would have been impossible to conduct were chosen because publishers primarily used acidic paper and continue to do so. Polish materials were evaluated because the overall quality of their publications appears to have improved since the collapse of the communist-led government. Therefore, the survey evaluated publications that could be considered among the "best" and "worst" of the Slavic publishing world. This was done to provide the most balanced view possible of the condition of Slavic publications.

For each item in the survey, a number of factors were evaluated including type of volume and size; type of binding, including leaf attachment and cover material; quality of paper; condition of paper, text block, and binding; and overall condition of the publication. To ensure that the survey results would be statistically valid, at least three hundred books published in Poland and three hundred books published in Russia, the Soviet Union, and/or the successor states were evaluated. In the end, 379 Polish and 476 Russian/Soviet items were randomly sampled from the collections. The results of the survey were rather surprising. To use an old saying, there is good news and bad news. 


\begin{tabular}{|lcc|}
\hline \multicolumn{3}{|c|}{ TABLE 2 } \\
\hline \hline Imprint Statistics \\
\hline Imprint Date & Polish & Russian \\
\hline $1830-49$ & $0.25 \%$ & $0.42 \%$ \\
$1850-69$ & 0.76 & 0.84 \\
$1870-89$ & 2.02 & 1.89 \\
$1890-1909$ & 2.52 & 5.04 \\
$1910-16$ & 0.76 & 2.73 \\
$1917-29$ & 3.53 & 2.94 \\
$1930-49$ & 3.27 & 4.62 \\
$1950 \mathrm{~s}$ & 9.82 & 9.66 \\
$1960 \mathrm{~s}$ & 18.39 & 18.28 \\
$1970 \mathrm{~s}$ & 28.21 & 14.71 \\
$1980-1984$ & 7.30 & 7.14 \\
$1985-1990$ & 11.08 & 13.66 \\
$1991-$ & 12.09 & 18.07 \\
$\mathbf{1 9 6 0}-$ & $\mathbf{7 7 . 0 8}$ & $\mathbf{7 1 . 8 5}$ \\
\hline
\end{tabular}

\section{Results from the Condition Survey of Slavic Materials}

Based on the results of this survey, which must be emphasized as only the initial step in a fuller evaluation of Slavic materials, the overall condition of Slavic publications is not as bad as many in the field fear. The survey revealed that 84.1 percent of Polish materials and 60.7 percent of Russian/Soviet materials are in overall good condition. This means that the publication is currently in no need of preservation treatment. The bad news is that over 95 percent of both the Polish and Russian/Soviet holdings are printed on acidic paper. Although the vast majority of this paper is not currently brittle, it will become brittle at some point in the future-in perhaps as few as twenty years. These brittle and acidic materials must undergo treatment if they are to be preserved for use by future generations of scholars.

Beginning with the imprint statistics, over 70 percent of the Russian and Polish collections were printed in 1960 or later (see table 2). ${ }^{5}$ However, it should be noted that an older publication date does not equate to the book being brittle. Many of the books published in the nineteenth century were published using high-quality materials. As a result, they remain in good condition.

Table 3 compares the percentage of brittle volumes by publication date for the two collections surveyed. As can be seen, the date of publication is a very good predictor of paper condition. As expected, preindustrial paper (before 1869) is generally strong. By contrast, the oldest machine-made, wood fiber papers (18701909 ) and early Soviet-era papers (1917$1929)$ are the most embrittled. This information should prove useful in generally predicting the condition of volumes printed during these various eras.

The result that will be of most interest to librarians is the condition of the paper in Slavic collections. After all, poor binding and other physical problems can be readily corrected as long as the paper in the publication is not brittle. Table 4 shows the results using a standard double-fold test for brittleness. According to these results, conditions are not too bad. Generally speaking, paper is considered brittle when it breaks after less than two double-folds. Only 2.26 percent of the Polish materials are brittle. This figure is actually lower than the amount of brittle materials found in the University of Kansas Libraries' overall collection. The Russian collection fares worse with 17.43 percent of the collection rated as brittle. ${ }^{6}$

\begin{tabular}{|c|c|c|}
\hline \multicolumn{3}{|c|}{$\begin{array}{c}\text { TABLE } 3 \\
\text { Percentage Brittle Volumes, } \\
\text { by Date } \\
\end{array}$} \\
\hline & Polish & Russian \\
\hline $1830-49$ & $0.0 \%$ & $0.0 \%$ \\
\hline $1850-69$ & 0.0 & 0.0 \\
\hline $1870-89$ & 12.5 & 33.3 \\
\hline 1890-1909 & 10.0 & 50.0 \\
\hline $1910-16$ & 0.0 & 61.5 \\
\hline $1917-29$ & 14.3 & 78.6 \\
\hline $1930-49$ & 7.7 & 27.3 \\
\hline $1950 \mathrm{~s}$ & 5.1 & 17.4 \\
\hline $1960 \mathrm{~s}$ & 1.4 & 28.7 \\
\hline $1970 \mathrm{~s}$ & 0.0 & 22.4 \\
\hline 1980-1984 & 0.0 & 2.9 \\
\hline 1985-1990 & 0.0 & 0.0 \\
\hline $1991-$ & 0.0 & 0.0 \\
\hline
\end{tabular}




\begin{tabular}{|lcc|}
\hline \multicolumn{3}{c|}{ TABLE 4} \\
\multicolumn{3}{|c|}{ Paper Fold Test (paper breaks after) } \\
\hline \hline & Polish & Russian \\
& $(\mathrm{N}=379)$ & $(\mathrm{N}=476)$ \\
\hline Less Than 1 Fold & $0.50 \%$ & $2.10 \%$ \\
Less Than 1 Double-fold & 0.50 & 5.67 \\
Less Than 2 Double-folds & 1.26 & 9.66 \\
Less Than 3 Double-folds & 1.76 & 6.09 \\
More Than 3 Double-folds & 95.97 & 76.47 \\
\hline
\end{tabular}

Over 86 percent of Polish and 43 percent of Russian acquisitions were printed on acid-free paper. The sampled Polish books with an imprint date of 1996 or later were all produced on acid-free paper. However, Russian publishers are more sporadic. For example, some high-quality academic books are still being printed on acidic newsprint, whereas some short-run, pamphlet-type publications are

The $\mathrm{pH}$ balance of paper plays an important role in the quality and life span of a publication. The more alkaline the paper, the less likely it will become brittle and the longer the publication will last. Unfortunately, Slavic materials fared poorly on the paper $\mathrm{pH}$ test (see table 5). These statistics are similar to the results of a small survey conducted by the AllRussian State Library for Foreign Literature in Moscow. That survey's results showed that 93 percent of all Russian/ Soviet materials published between 1860 and 1985 were printed on acidic paper. Between 1990 and 1995, this figured dropped to 84 percent of all items published on acidic paper. ${ }^{7}$

Fortunately, the trend to use acid-free paper is continuing, as indicated in the results of the University of Kansas survey. There has been a significant increase in the use of acid-free paper in both Poland and Russia. Since 1991, over 29 percent of all volumes published in Poland and over 15 percent of all volumes published in Russia have been printed on acid-free paper. Furthermore, a test evaluating the condition of all new Polish and Russian acquisitions at the University of Kansas Libraries during spring 1998 revealed an exponential improvement.

printed on acid-free paper.

Perhaps the sporadic use of acid-free paper in the Russian publishing industry can be explained by two reasons. First, the current economic situation forces many Russian publishers to use any type of paper available. Second, Russian publishers in general are not overly concerned about the life span of their products. In October 1997, very few publish-

\begin{tabular}{|lcc|}
\hline \multicolumn{3}{|c|}{ TABLE 5 } \\
Paper pH \\
\hline \hline & Polish & Russian \\
\hline Acidic & $94.71 \%$ & $87.18 \%$ \\
Slightly Acidic & 1.01 & 8.82 \\
Alkaline & 4.53 & 3.99 \\
\hline
\end{tabular}

ers expressed interest in attending a conference held in Moscow to discuss the use of permanent (acid-free) paper. Many publishers did not know about acid-free paper, and still others felt that preservation issues were not their affair. ${ }^{8}$

Another factor that determines a publication's durability is the quality of its binding. A good binding can extend the life of a publication, even if the publication is printed on acidic paper. The results of this survey indicated that bindings of Slavic materials do not

\begin{tabular}{|lcc|}
\hline \multicolumn{3}{|c|}{ TABLE 6 } \\
Condition of Binding \\
\hline \hline & Polish & Russian \\
\hline In Good Condition & $87.15 \%$ & $56.51 \%$ \\
Sent to Stacks as is & 5.79 & 39.71 \\
Needs Preservation Treatment & 7.05 & 3.78 \\
\hline
\end{tabular}
break down as quickly as one might expect (see table 6). Clearly, the Polish bindings rank far higher in quality to their Russian counterparts. Although many of the Russian bindings were not in good condition, they remain strong enough to return to the stack for 


\begin{tabular}{|lc|}
\hline \multicolumn{2}{|c|}{$\begin{array}{c}\text { TABLE 7 } \\
\text { Place of Printing }\end{array}$} \\
\hline \multicolumn{2}{|c|}{ Polish } \\
\hline Warsaw & $56.93 \%$ \\
Wroclaw & 13.85 \\
Krakow & 11.34 \\
& Russian \\
\hline Moscow & $61.34 \%$ \\
Leningrad/St. Petersburg & 16.81 \\
Kiev (Ukraine) & 6.51 \\
\hline
\end{tabular}

further use before needing preservation treatment.

Only a few cities in each country published a majority of the volumes housed in the collections. This information will be useful for establishing future cooperative preservation activities with publishers and libraries (see table 7).

As the final step in the survey process, each item received an overall preservation treatment recommendation. Again, these results show that things are not as hopeless as sometimes feared, with less than seven percent of items surveyed needing some kind of immediate preservation treatment. This figure almost doubles the results obtained for the University of Kansas's overall library collections but still represents a manageable number of volumes (see table 8). ${ }^{9}$

The results of this survey should lend hope to preservation efforts. Most of the items sampled are in acceptable condition and can be preserved before it is too late, particularly if libraries make efforts to work cooperatively to maximize collective resources.

\section{What Is to Be Done?}

This survey is the first step in evaluating the quality of Slavic collections. Additional work needs to be completed, including the evaluation of more sections of the Slavic holdings at the University of Kansas Libraries. More important than this is the evaluation of Slavic collections held in other libraries. Evaluations of the condition of general collections in research and academic libraries have been conducted, but these surveys do not report any specific findings on the condition of Slavic holdings. The results from these general evaluations indicate that the percentages of material needing preservation vary by institution, based on geographic location of the library and the quality of the storage facility. This suggests that surveys on Slavic holdings will produce similar varying results. Finally, the most important step will be to evaluate holdings "in-country" (in Russia, Ukraine, Poland, and elsewhere in East Central Europe) to gain a true idea of the overall condition of Slavic collections. Information accrued from these evaluations will enhance our understanding of the challenges inherent in attempting to preserve Slavic publications.

Based on this initial survey, Slavic publications do not appear to be as fragile as often believed. Working to preserve collections is not yet at the point of crisis, and there is still time to consider preservation options. However, it is clear that preservation planning and work need to begin now, before materials deteriorate to the point where they cannot be saved. Steps must be taken to preserve these resources collectively because it is not feasible to expect each library to have the resources available to preserve all of its holdings individually.

Currently, a number of vendors such as East View Publications, IDC, Chadwick-Healey, and Norman Ross actively film Slavic titles. However, vendors tend to focus on the preservation of bigticket items such as newspaper runs or multivolume publications. Naturally, the vast majority of Slavic publications do not fall into this category. Moreover, not ev-

\begin{tabular}{|lcc|}
\hline \multicolumn{3}{|c|}{ TABLE 8 } \\
Treatment Decision for Volume \\
\hline \hline & Polish & Russian \\
\hline In good condition & $84.13 \%$ & $60.71 \%$ \\
Sent to stacks as is & 9.82 & 34.03 \\
Needs preservation treatment & 5.54 & 6.72 \\
\hline
\end{tabular}


erything published in the Soviet Union and its successor states needs to be preserved, although much does. Thousands of publications provide valuable insight into the Soviet system and the development of the subsequent independent states. It would be unfortunate for future students and scholars of the region if libraries allowed these books to disappear through neglect.

Of course, the preservation of Slavic materials is not simply limited to vendor projects. Many libraries have preservation programs in operation. In addition, there are a number of cooperative preservation programs such as the Slavic and East European Microfilm Project (SEEMP) at the Center for Research Libraries and the independently operated SlavCopy cooperative program.

SEEMP, like vendors, has thus far focused on the preservation of big-ticket publications. It provides libraries with the opportunity to pool their Slavic collection resources, both materials and money, to preserve items that individual libraries would be unable to save on their own. Member institutions of SEEMP propose and work on joint preservation projects. For example, a library may have an incomplete run of a newspaper. Through the coordinated efforts of SEEMP, other libraries' holdings can be used to fill in these gaps.

SlavCopy is another coordinated program that allows libraries to preserve Slavic publications cooperatively and economically on a title-by-title basis. ${ }^{10}$ Books that cannot be preserved commercially (i.e., that cannot be sold to recoup expenses and a profit for the vendor) can be saved through archival quality photocopying. Companies such as Bridgeport National Bindery in Agawam, Massachusetts, are willing to make as few as one high-quality copy of a book that is no longer covered by copyright laws. Participation in SlavCopy allows libraries to coordinate their preservation activities and reduce Slavic preservation costs through group/volume discounts. Each library has the responsibility to identify important publications in its collections in need of preservation treatment and submit the title to the SlavCopy electronic mail list. Other libraries can then order a copy of the item, thus reducing costs for every institution involved. Currently, SlavCopy participants are limited to North America. The program needs to investigate ways to expand its efforts to include libraries in East Central Europe. These cooperative programs are the most efficient and cost-effective methods to preserve our collections and should be used to their fullest advantage.

In general, the results of this preliminary study indicate that the majority of Slavic area materials are currently in acceptable condition. However, the statistics prove that the majority of the publications are printed on acidic paper, which means they will deteriorate rapidly. Our tasks are to provide proper housing and maintenance to delay deterioration and to reformat those materials that have surpassed their usable shelf life. Libraries must work collectively to combat this problem because no one library can do it alone.

In the history of mankind, there has never been greater period of publication than the twentieth century. The responsibility for collecting the millions of volumes of works includes the extraordinary task of preserving them for future generations. If this responsibility is taken lightly, important parts of our history will be lost in the dustbin. In the area of Slavic studies, acidic paper is statistically the greatest threat to preservation. Although the tide is turning and publishers are using acid-free paper more frequently, the damage is done on the Soviet-era publications. It is up to us to save what we can. As this study shows, only a few materials are in need of immediate attention. This gives us time to devise collective preservation strategies for the majority of our Slavic collections before they begin to crumble on the shelves. Cooperative programs will provide the most efficient and cost-effective ways to preserve these collections. We must work to build these programs now. 


\section{Notes}

1. For an excellent short description of the condition of Russian libraries, see Galina Kislovskaya, Preservation Challenges in a Changing Political Climate: A Report from Russia (Washington, D.C.: The Commission on Preservation and Access, 1996), 4-5.

2. See, for example, James M. Reilly, Douglas W. Nichimura, and Edward Zinn, New Tools for Preservation: Assessing Long-Term Environmental Effects on Library and Archives Collections (Washington, D.C.: The Committion on Preservation and Access, 1995).

3. Ani Gergova et al, National Program for the Preservation of Library Collections (Sofia: Union of Librarians and Information Services Officers and Open Society Foundation, 1997); Kislovskaya, Preservation Challenges in a Changing Political Climate.

4. Brian Baird, Jana Krentz, and Brad Schaffner, "Findings from the Condition Surveys Conducted by the University of Kansas Libraries," College \& Research Libraries 58 (Mar. 1997): 115-26.

5. Most of the material published between 1830 and 1869 would be housed in the KU Rare Books Library.

6. The University of Kansas Libraries' percentages of embrittled volumes is sure to be much lower than those found by other research libraries around the country. This conclusion is based on the fact that the University of Kansas Libraries' overall condition survey showed that only six percent of its collections are brittle. Other libraries throughout the country have found that as much as 25 percent of their collections are brittle. Therefore, one can expect to see a proportional increase for the brittleness of Slavic materials. Such an increase will dramatically increase the number of brittle Slavic materials in some library collections. See Baird, Krentz, and Schaffner, "Findings from the Condition Surveys," 122.

7. Kislovskaya, Preservation Challenges in a Changing Political Climate, 18.

8. "Permanent Paper Conference Aims to Raise Awareness in Russian," Preservation \& Access International Newsletter, no. 1, Mar. 1998. Available at: http://www.clir.org/pubs/pain/ pain01.html.

9. Baird, Krentz, and Schaffner, "Findings from the Condition Surveys," 121.

10. Libraries can participate in Slavcopy by sending an e-mail to: Slavcopy@ukans.edu. 